\title{
Investigating The Influence of Virtual Reality Technology in Teaching and Learning: From Perception of Nigerian Junior High School Students
}

\author{
Enyiazu Franca Adanne \\ faculty of Education, Southwest University \\ No. 2 tianshang Road, Beibei District, Chongqing 400715, P. R. China \\ E-mail: francaenyiazu@gmail.com
}

\begin{abstract}
It was relevant to investigate integrating virtual reality technology and education teaching, claiming that VR technologies are essential for teaching and learning. Therefore, the study was conducted in Abuja, Nigeria, to assess how much VR technologies could be practical tools to improve teaching and learning at the junior high school level from learners' perspective. Fifty-six students were randomly selected from 5 public junior high schools to use VR goggles to play games, watch videos, and see photograph contents based on virtual environments. As a result, it was discovered that the participants expressed a high level of appreciation of VR applications which could be attributed to the fact that more than three-quarters of the participants had never previously tried them either for educational or entertainment purpose. Moreover, based on their experience, an overwhelming majority of the participants ultimately agreed that VR technologies as instructional tools would be very effective in visualizing abstract concepts for practical understanding, making learning more interactive, encouraging active participation rather than passivity, and making learning more exciting and fun.
\end{abstract}

Keywords: Virtual Reality, Education, Instructional tools, Nigeria.

DOI: $10.7176 / \mathrm{JEP} / 12-18-04$

Publication date:June $30^{\text {th }} 2021$

\section{INTRODUCTION TO BACKGROUND OF STUDY}

The need to make teaching and to learn very effective for both teachers and learners has led to several efforts made by learning theorists and educational experts to discover or devise teaching and learning methods that interact and experience its goal. Theorists and learning experts who believe in experiential learning as the most effective learning method assert the idea that learners have to be engaged in active processes as this enhances their knowledge acquisition process (Sharma, Agada, \& Ruffin, 2013). Thus, getting learners involved in manipulative strategies is crucial to learning has been widely acknowledged as a very effective method. The conviction that all learners' senses have to be involved more excitingly has led to the adoption and application of virtual reality (VR) technologies as instructional tools in education. VR technology is considered a necessary educational tool. It allows a user to interact with a computer-simulated environment, whether that environment is a simulation of the natural world or an imaginary world. It is the key to experiencing, feeling and touching the past, present and future (Budziszewski \& Cheung. et al. 1, 2013).

Notwithstanding, there are still mixed views about how much they use of VR technologies can help improve teaching and learning in schools and universities in Nigeria. Research indicates that technology is widely used in entertainment and engineering than education (Wiecha, Heyden, Sternthal, \& Merialdi, 2010). VR technologies are far more used in developed countries than in developing countries; the focus of this study is to assess the potential impact of the application of VR technologies in the field of education in Nigeria as a developing country. Nigeria is known as a developing country in West Africa, where technology is less advanced. As a result, many economic, health, and educational activities in Nigeria depend less on advanced technology and traditional methods.

VR technologies in education teaching are advancing based on the perception that the technology would enable a positive internal or personal learning experience for the user than what is traditionally available. It is believed that the use of VR applications in education will bring several gains to teachers and learners, including excitement, motivation to learn, deeper learning and long-term retention, and increased time-on-task. It is also believed that VR technologies will be perceived as essential teaching and learning tools in the future. However, just like many other technologies, research indicates that VR technologies in education are still not widespread globally, especially in developing countries like Nigeria that depend more on traditional methods than advanced technologies. Even though many educational institutions in Nigeria have improved the use of information technology over the years and operate e-learning centres that enable them to run distance education, VR technology is widely accepted and used for teaching and learning. Therefore, the benefits of VR technologies in education are yet to be fully realized and appreciated across the country. Therefore, to recommend VR technology as a necessary tool for experiential education to educational policy-makers in Nigeria, this study 
examines how much virtual reality technologies will improve teaching and learning in schools and universities.

It is relevant to conduct empirical investigations into the integration of virtual reality technology and education teaching because VR technologies are increasingly being considered essential tools for instruction in education teaching. Furthermore, it is perceived that more and more educational institutions worldwide utilise VR technologies as necessary educational materials for teaching and learning. Therefore, the results of this study will be essential as a contribution to the literature and knowledge on the academic importance of VR technologies. The purpose of this study is to assess how much VR technologies can be used as practical tools to improve teaching and learn at the junior high school level of education from learners' perspective in Nigeria. The following questions are raised for investigation in other to achieve the purpose of the study:

1. What are the views of learners about the superior aspects of VR applications in learning?

2. What multimedia items in VR applications make their use more exciting and effective to learners?

3. What are the participants' views towards the effectiveness of VR technologies as an interactive instructional tool?

This study was limited in scope to a few public educational institutions in Nigeria and a small number of junior high school students due to the influence of the Covid-19, which caused limited access to more schools.

\section{LITERATURE REVIEW}

Definition of Virtual Reality

A review of the literature shows that Virtual Reality (VR) is the term used to describe a three-dimensional, computer-generated environment that can be explored and interacted with by a person. That person becomes part of this virtual world or is immersed within this environment and, whilst there, can manipulate objects or perform a series of actions (Kong. et al. 1, 2014, \& Chung, 2012). In other words, VR is defined as immersive, realistic, three-dimensional environments involving visual feedback from body movement (Aarseth, 2001). According to Haluck (2000), VR can be categorized by three basic principles; a) immersion, in which users have a natural sensation of being inside the virtual world through devices such as a digital helmet or digital cave; b) interaction, whereby users can manipulate virtual objects through devices such as digital gloves; and c) involvement, in which users can explore the virtual world using taking part in the virtual world, interfering directly in the result of the application, and navigate the virtual environment either passively or actively. Today, virtual reality is usually implemented using computer technology. A range of systems is used to use headsets, Omnidirectional treadmills, and special gloves. These are used to stimulate our senses together to create the illusion of Reality (Hsieh, Wub, mac, 2010 \& Jacobson et al., 2005).

\section{The Prospects of Virtual Reality in Education}

For educational purposes in general, VR technology has been widely proposed as a significant technological breakthrough that possesses an immense potential to facilitate learning as the technology allows students to step through the computer or television screen into a 3-D computer-simulated world to learn. Furthermore, due to its interactive nature, several educationists and researchers postulate that VR could make learning more exciting and fun, which could indirectly increase students' motivation and attention. A famous advocate of this perception is Clark. According to Clark, virtual reality technology can make learning more exciting and fun to improve motivation and concentration, decreasing costs when using the objective and the actual environment no matter how expensive the simulation is. Clark further explains that VR presents an opportunity of learning with an existing situation but artificially created, facilitating the visualization and the interaction sensation with the study focus. This means that when we cannot have real experiences, virtual Reality is irreplaceable. Furthermore, virtual reality simulation also permits us to be in complex and dangerous situations, which are not usually accessible in the real world.

Virtual Reality encourages active participation rather than passivity. The participant who interacts with the virtual environment is encouraged to continue interacting by seeing the results immediately. It provides an opportunity for the learner to make discoveries previously unknown. New perspectives are made possible by modelling the real world, and studying the model can provide insights never before realized. Virtual Reality allows the disabled to participate in an experiment or learning environment when they cannot otherwise (Boyle, 2016). There are many essential types of research in the literature to mention. Researchers including Aarseth (2012), Clark (2006), Howe (2000) \& Wadhera (2016) referred to the use of VR technologies with instructional purposes, as well as in the areas of entertainment, military and industry. In this context, the present research argues that using VR technologies in classes mainly in the social context can be more appropriate and effective. It is thought that VR technology will primarily affect the inner motivation of learners positively, especially in classes such as history and geography, which requires verbal content and visualization of past events. Hence, it can be said that the utilization of VR technologies in social classes like history and geography can be positive and motivating elements that will lead to positive results. It is also seen that VR technologies can be used in a wide range of areas, from science to music. The utilization of VR environments in the learning process is 
thought to provide particularly permanent learning experiences, which can be explained by the fact that users' present in that environment and/experiences it by himself/themselves. It is thought that the participants desire to take part directly in the learning process and activities, which is why they are more likely to appreciate the technologies that enable it. Kaufmann \& Meyer (2009) Stated that VR environments isolate users from the real world, which increases their attention towards the content presented. Therefore, it is essential for users participating in the process to think that VR technologies will provide permanent learning, a crucial element in education. Other findings of the VR technologies' impact on endless learning support this claim (Clark, 2006 \& Boyle, 2016). The VR technologies are also able to create funny and easy learning environments. Wadhera (2016) Notes that VR technology can make more accessible and more comfortable learning environments. Some research in the field highlights that VR supported education increases motivation, provides a fun, and allows experiencing. According to Clark (2006) \& Howe (2000), VR technologies can influence learners' motivation positively. However, they also state that some experiences in VR environments may not perfectly fit the real world, so users who succeed in the VR environment may not exhibit the same success in the real world. Besides, it is understood that VR technologies increase the desire to learn and curiosity in users. It can be said that VR technologies are seen as essential tools that have any contents which are not possible to be experienced in the class environment for various reasons. Clark (2006), Strauss (2000) \& Boyle (2016) state that VR technologies can be used when the utilization of natural objects or accurate word is extremely hard or impossible, and when using the real thing is insecure or very costly. Besides, the sense of Reality presented by VR environments can be very effective in learning environments. They also believe that the inclusion of real-like visuals and devices in the system strengthened the teaching process, made it easier for users' adapt to the settings, and quickly changed their roles according to the evolving circumstances. We need to adopt VR technology in education teaching because students of the current generation are millennials. Among the many traits of millennials, they spend most of their time online, and some live in the virtual world. It has to be acknowledged that since these millennials spend most of their time online and are avid users of interconnected mobile devices, teachers need to consider having teaching materials and learning activities with similar attributes, and this underscores the use of VR technologies (Wadhera, 2016 \& Hu-Au, 2017).

\section{Factors Limiting the Use of Virtual Reality Technology}

Notwithstanding the many gains of VR technology, research shows that the use of VR technology across the world is not widespread due to several challenges and limitations to the technology itself. Notably, studies indicate that its widespread adoption in developing countries is yet to happen, although this technology has existed for more than half a century (Scott, 2015, Takala, 2014 \& Kavanagh. et al., 2017). The factors that account for the limited adoption and use of advanced technologies such as VR technology can be categorized into technological, organizational, and environmental challenges. In other words, it can be explained that the process by which an organization, including educational institutions, adopts and implements technological innovations is influenced by technical, organizational, and environmental challenges. The technical factors describe the internal and external technologies that are relevant to the organization. Therefore, it includes existing technologies inside the organization and the pool of available technologies in the market.

Concerning VR technology, the technical challenges could be speed interoperability, hardware, software, security, and connectivity problems. Learning centres and institutions that adopt advanced technology for virtual learning also require students to have efficient and effective ICT skills to take advantage of these benefits (Budziszewski, 2013). Organizational factors that affect advanced technologies include institutional and administrative challenges, implementation challenges, financial challenges, and time management challenges. The environmental context consists of the size and structure of an organizations' competitors, the macroeconomic context, and the regulatory environment. Previous studies on environmental factors have looked at competitive pressure, the regulatory environment, and consumer readiness. Additional factors include stakeholder involvement, stakeholder participation and cultural influences (Gomes, Oh, Chisik, \& Chen, 2012). Adding to these, Takala (2014) found that VR technologies usage and adoption varied between universities. Their study specifically revealed several factors that hinder the adoption and delivery of virtual learning in Africa. These include inadequate training and support for ICT, poor content-creation skills, policy, cost, technological barriers, access to diverse populations, large class sizes, infrastructure and technical issues, instructor motivation, and job security. Kiss (2012) also shows that significant numbers of people encounter challenges when using VPs, especially e-learning and e-business. They have inadequate skills and lack the skills to engage meaningfully within online communities. Beyond these, other limitations affect users' preference for VR technologies, and these include resolution, image quality. It can be said that the most important ones are the low resolution and image quality problems in the content. It is thought that the inherent defects in resolution and image quality prevent the feeling in ambience and Reality, which are considered as the most critical superior aspects of enjoying VR technologies. In addition, it has been seen that VR technologies are directly related to the suitability of image quality which is considered as the primary determinant in assessing effectiveness. For this 
reason, it is considered that the content to be used should be vivid with high resolution, which affects the users' preferences (Gome et al. 2012 \& Fabola, Miller, 2016). It has also been pointed out that the visual quality of virtual VR technologies could be lower than the actual conditions, which would cause some problems that the users would deal with. Additionally, interactivity is determined as an essential factor in VR technologies. Inadequate interaction can affect participants' preferences (Weng, Yang, Ho, \& Su, 2018). Sherman and Craig (2002) also emphasized in their research that interactivity is one of the four essential characteristics of VR. They also stress that designers are working extensively on inadequate interaction, which is one of the most significant limitations of VR technologies. It can be said that VR technologies can cause some physical effects as well (eye burn, dizziness, etc.). This can reduce the effectiveness of VR technologies in long-term usages.

\section{Research Gap in the application of VR technologies in education}

After examining the literature, it is clear that the gains of VR technologies include interaction, excitement, deeper learning and long-term retention. Considering these gains, VR technologies have been highly recommended for use in education. In this regard, several researchers have conducted studies on the educational orientations of VR technologies. While some researchers have focused on the specific educational practices of VR technologies, others have investigated various environments of VR technologies in the fields of history, geography, science, and mathematics. However, the effectiveness of VR technologies in improving the teaching and learning of all subjects in schools and universities across the world continues to be questioned. Moreover, empirical studies that provide evidence to how much VR technologies can improve learners' knowledge and critical thinking skills in developing countries where acceptance and use of this advanced technology are still challenging appear inadequate. Thus, this study focused on assessing how much VR technologies can improve teaching and learning at Nigeria's junior high school level.

\section{METHODOLOGY}

This study used a case study design. A case study is a research design that entails detail and intensive analysis of a case constructed to richly describe, explain, or assess and evaluate a phenomenon such as an event, community, organization, group, person, program, etc. (Yin, 20103). The term "case" is often used to refer to a location, such as a community or an organization. However, according to Bryman, the emphasis tends to be upon an intensive examination of the setting (Bryman, 2008). This design allows the researcher to select a few public junior high schools in Abuja, Nigeria, as a case study. A research strategy is a general plan that helps the researcher answer the research questions systematically (Creswell \& Plano Clark, 2011). Students from the selected schools were taken through virtual reality lessons to answer VR and education teaching integration questions. Each of them was asked to describe their experiences. The participants were made to use VR applications on a mobile device via virtual goggles. The quality of the applications and their suitability based on the level of the participants were determined before the implementation.

Target population has been used to refer to the group of people from which sample size is to be drawn (Creswell, 2009). The study's target population was public junior high schools in Abuja, Nigeria. Statistics from the federal ministry of education (2020) revealed more than 100 public junior high schools in Abuja. Determining sample size is necessary when researchers cannot study everyone in the target population. Due to limited resources to involve many participants and the need to obtain qualitative data to enhance the results, only 56 students were selected randomly from five (5) schools to participate in the study.

The study relied mainly on primary data gathered directly from the study participants to answer the research questions designed to assess the effectiveness of VR technologies in education teaching. According to Malhotra \& Birks (2007), primary data can be identified as data from the researcher to address the research problems. Hence, primary data is original material that has not been interpreted by anyone other than the researcher. The researcher collected this data through practical activity and structured interviews designed to find answers to the research questions on the use of VR technology for instructional purposes. It is widely acknowledged that interviews effectively collect in-depth data (Voss, Tsikriktsis, \& Frohlich, 2002). Prior to the administration of the interviews, the participants were informed about the purpose of the study and how they were chosen to participate in the study. They were assured of the confidentiality and anonymity of their identity and responses. All required conditions and laid-down procedures in researching public schools in Nigeria were followed. The researcher designed the interview guide. It included demographic features of the participants and questions to elicit the individual experiences and views of the participants about VR technology after each application was used to undertake the stated lessons. The participants were given contents of applications in three categories game, video, and photographs. They viewed these contents through virtual reality goggles, and their views were examined based on the research questions. The chosen VR application contents were the following:

\section{- The game category}

Game 1: a game of fishing that provided three different environments played through a touch keypad superimposed on the VR goggles. 
Game 2: a game that allowed the participants to see inside cells.

\section{- The video category}

Video 1: an animation video that allowed the participants to watch the appearance and movement of an elephant in the forest.

Video 2: a documentary video on a volcanic eruption.

Video 3: video of submarines in an environment made of animated images that enabled the participant to watch them underwater.

\section{- Photo category}

Photograph: this application was made up of images created with 3D and used to monitor some historical and famous places in Japan.

Content analysis was used to analyze the data obtained from the participants through interview. The researcher coded the data, and related codes were grouped and categorized. The categories and their frequency and percentage values are presented interpreted. The opinions of the participants are directly included. Data were sorted out using the below listed systematic model:



source: generated by the Researcher, 2021

\section{PRESENTATION AND ANALYSIS OF RESULTS}

\section{Overview}

The study assessed how much VR technologies could be used as practical tools to improve teaching and learn at the junior high school level of education from learners' perspective. A sample of 56 participants selected from 5 public junior high schools in Abuja was made to play games, watch videos, and see photographs of selected contents through virtual reality goggles. Their views were examined to find answers to the following questions, which were raised for investigation:

1. What are the views of learners about the superior aspects of VR applications in learning?

2. What multimedia items in VR applications make their use more exciting and effective to learners?

3. What are the participants' views towards the effective use of VR technologies as an interactive learning tool?

First of all, the demographic characteristics of the participants are presented and interpreted. A sample of 56 students was selected at random from 5 public junior high schools within Abuja. The socio-demographic characteristics of the participants that were of interest to the study were age, gender and class level. Data relating to these demographics are presented and described. The participants were asked to indicate their ages. Figure 4.1 below illustrates a distribution of the ages of the respondents under three age ranges: 


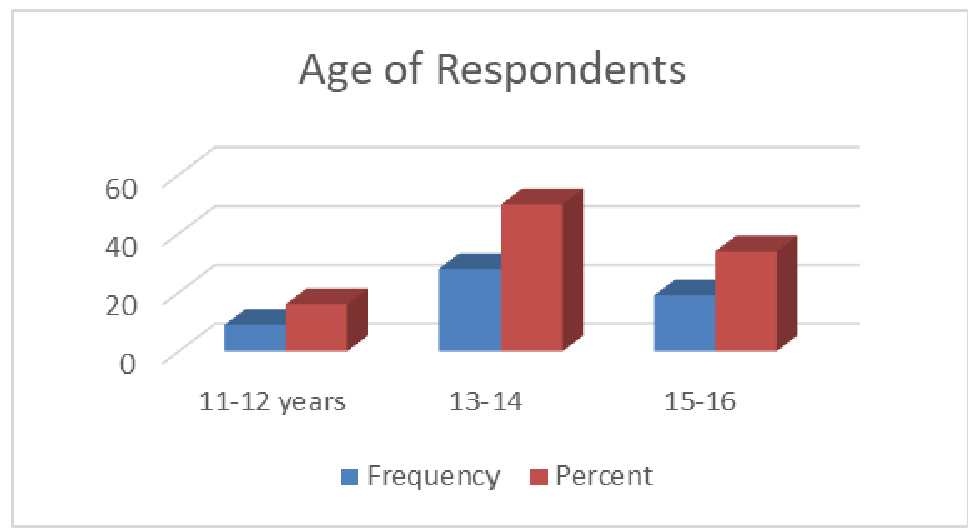

Figure 4.1 Age distribution

Source: Field data, 2021

Figure 4.1 shows that the majority $(50.0 \%)$ of the participants were aged between 13 and 14 years. Participants aged between 11 and 12 years were the least. The ages of the participants correspond with the aged standard set by the federal ministry of education for junior high school students, which is (aged 12-15).

Data relating to the gender of the participants is summarized in Figure 4.2 below:

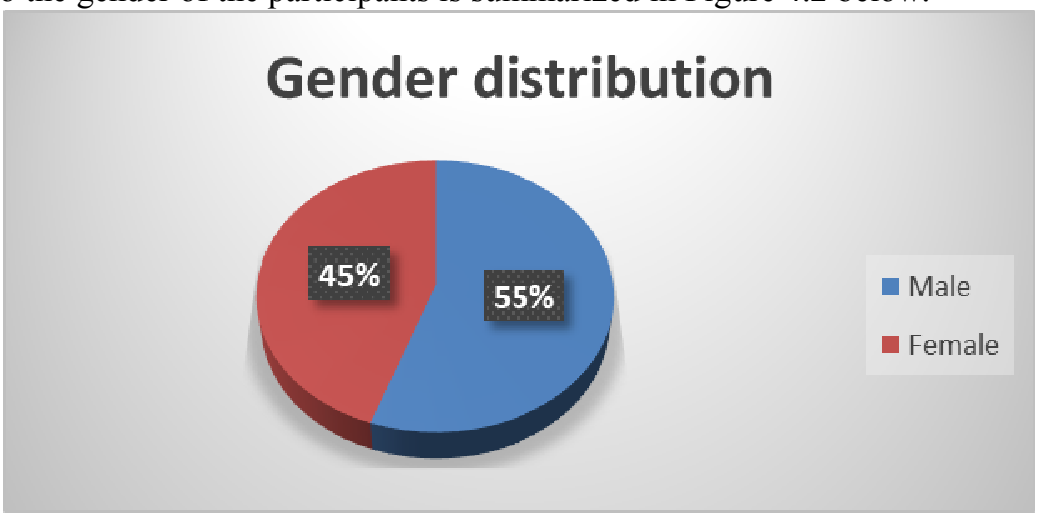

Figure 4.2: Gender distribution

Source: Field data, 2021

The data shows that the study was not gendered biased; instead, it involved both male and female students. However, the proportion of male students who took part in the study was more than females. This corroborates with already existing statistics that the proportion of males at all levels of education in Nigeria is more than female.

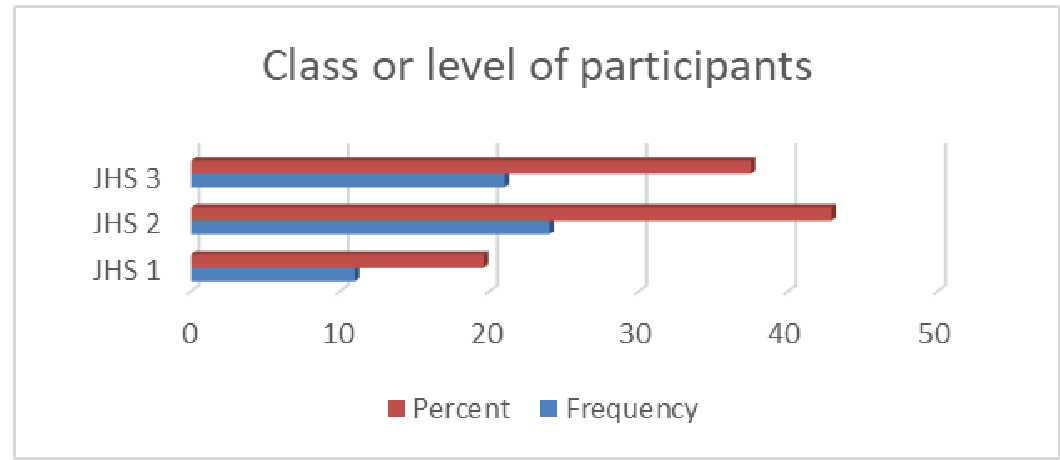

Figure 4.3: Class or level of participants

Source: Field data, 2021

Figure 4.3 shows that students of all junior high school levels from the various schools took part in the study, which implies that the results can be generalized as representing the views of junior high school students from the selected schools. However, the proportion of JHS 2 students who took part in the study was the highest while the least was JHS 1 students.

Participants' Views about the Superior Aspects of VR Applications in Learning

It was relevant to examine the participants' views about the superior aspects of VR applications in learning. To start with, virtual Reality (VR) was explained to the participants as "a three-dimensional, computer-generated 
environment which can be explored by a person that becomes part of this virtual world or is immersed within this environment. whilst there, can manipulate objects or perform a series of actions." Then, based on this definition, the participants were asked if they had used any VR technologies or devices to explore and interact with a VR environment previously or not. Surprisingly, it was discovered that none of the participants had once used any VR technologies to explore and interact with a virtual reality world. This, however, corroborates with existing research, which shows that the use of VR technology across the world has not been widespread due to several challenges and limitations to the technology itself. For example, a study done by Kavanagh, LuxtonReilly, Wuensche \& Plimmer (2017) reviewed that the widespread adoption of VR in education is yet to happen, although this technology has for more than half a century been in existence.

\section{Superior aspects of VR technologies indicated by participants}

A practical activity was undertaken in which all the selected participants were allowed to use VR goggles to explore and interact with virtual reality environments through playing games, watching videos, and seeing photographs. Afterwards, the participants were asked to indicate the superior aspects of VR technologies that they experienced. The data in Figure 4.4 shows that the superior characteristics of VR technologies experienced by the participants included a feeling of Reality, a sense of ambience, and the opportunity to tour.

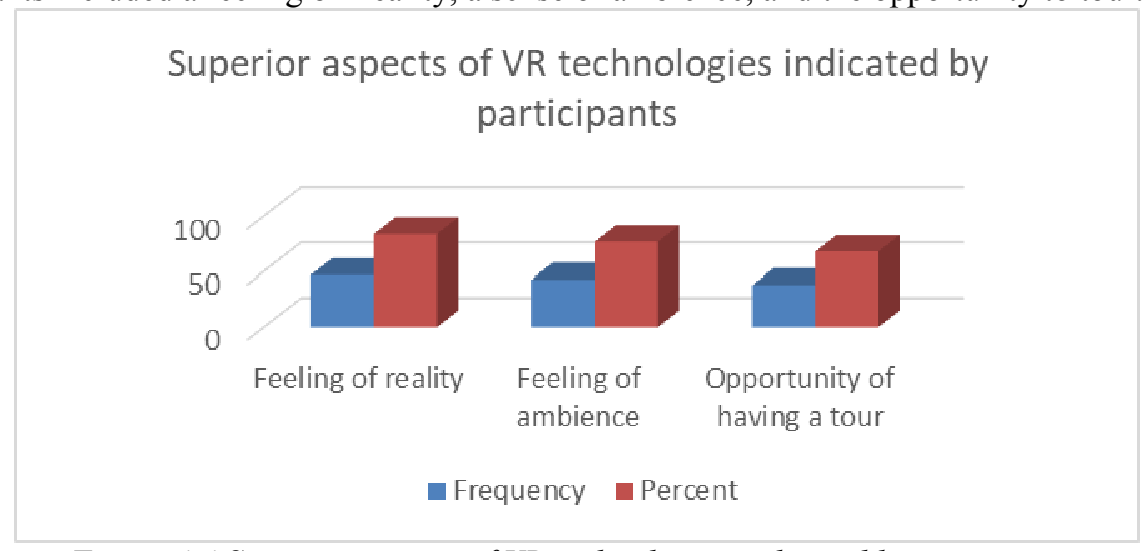

Figure 4.4 Superior aspects of VR technologies indicated by participants

Source: Field data, 2021

It was realized that the participants frequently mentioned and talked about the feeling of Reality. They noted that they were very excited and well entertained with the experience and that it was realistic. Many of the participants also showed frequently that VR technologies provided a feeling of being in ambience. Furthermore, participants emphasized that they were curious about the content and examined the environment presented in this regard to the finest detail. Lastly, several of the participants liked the applications because they offered them the opportunity to have an exciting tour of places that would not otherwise be possible for reasons of distance, timescale, safety, or money. Some views given by a few of the participants during the interview are the following:

"I was so afraid of the heights; it was too high when I found myself travelling to Japan. I had heard a lot about Japan and wanted to be there, but it was amazing that I could see Japan through these goggles just as if I was there. But I got so scared when I began to feel it was too high, but it was very nice" (User 6).

"The feeling I had was so real and exciting, especially when I was under the ocean and a shark approached and came into collision with me. There were some bubbles, and it was as if I was getting drowned" (User 3).

It was a beautiful experience. I felt like I was just up there. It looks like you are in that place as if you are one of the persons there. Those people there. I ask myself, "what is happening to me? Oh my God, where I'm I now?" (User 1).

\section{Participants' views on the limitations of VR technologies}

It was also essential to seek the views of the participants on the limitations of VR technologies. Based on their experience after use, they were asked to state any limitations of the technology. In response, the participants who found some limitations frequently mentioned low resolution, eye burns, insufficient interaction, dizziness, and isolation from the real world, as summarized in Figure 4.5 below. 


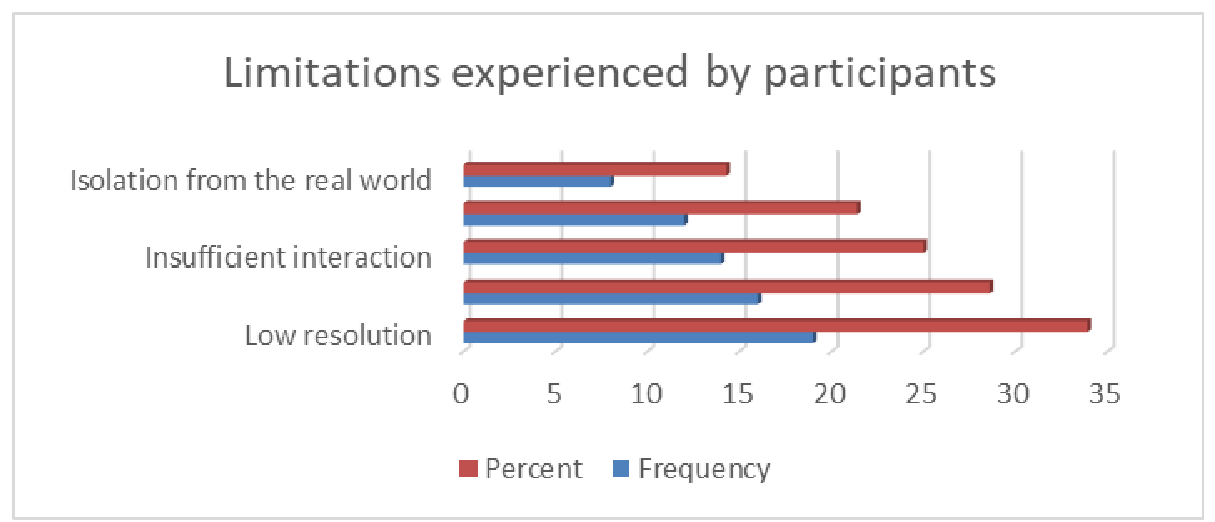

Figure 4.5: Limitations experienced by participants

Source: Field data, 2021

It was discovered during the interview that even though the participants highly appreciated VR technologies, they also experienced these limitations. When their views were examined, the most frequently mentioned limitation was low resolution, which implies that the resolution and the image quality of the contents offered were of much importance to the participants. Notwithstanding, the resolution was low, and there were defects in the quality of the image. To some extent, the low quality reduced the participants' appreciation of the contents. It was also realized that some of the participants experienced some eye burns and dizziness, which is a physical limitation of the technology. The remaining participants added that there was insufficient interaction with the contents presented. Regarding isolation, some participants expressed that VR technologies could take their users to the point where they could lose touch with the real world after some time. Some of the participants expressed their views as follows:

"It was so nice watching the volcanoes, although a bit scary. But it would have been much fantastic if the image quality had been a bit higher" (User 1)

"I liked everything, especially the video and the game, but I don't know why; my eyes were straining" (User 14)

"The goggles were wonderful, but I felt dizzy while I had them on. I don't know if it's because that's my first time wearing such goggles" (User 21)

"It was interesting, just that the pictures for me were not all that clear."

\section{Multimedia Items in VR Application Making Its Use More Interesting and Effective to Learners}

VR uses the entire spectrum of current multimedia technologies, including image, video, sound and text, and newer and upcoming media such as e-touch, e-taste, and e-smell. However, the impact of these multimedia technologies on using VR to learn is not the same. Thus, the second specific research question was about what multimedia technologies made VR more exciting and effective to learners. In light of this, the participants who were given several VR contents in several multimedia technologies, including games, videos, and image, were asked to indicate their level of preference for each of the media with regard to how it made the use of VR more exciting and practical to them as learners. Table 4.6 below is a summary of their preferences for the multimedia technologies used.

Table 4.1 Participants' preference for multimedia technologies used in VR

\begin{tabular}{|c|c|c|c|c|c|c|}
\hline \multirow[t]{3}{*}{ Media } & \multicolumn{6}{|c|}{ Level of preference } \\
\hline & \multicolumn{2}{|c|}{ A little } & \multicolumn{2}{|c|}{ Much } & \multicolumn{2}{|c|}{ Very much } \\
\hline & $\mathrm{F}$ & $\%$ & $\mathrm{~F}$ & $\%$ & $\mathrm{~F}$ & $\%$ \\
\hline Game & 3 & 5.4 & 12 & 21.4 & 41 & 73.2 \\
\hline Video & 2 & 3.6 & 8 & 14.3 & 46 & 82.1 \\
\hline Image & 31 & 55.4 & 19 & 33.9 & 6 & 10.7 \\
\hline
\end{tabular}

The data shows that the participants' preference for VR contents presented via video and game was much higher than the image. Thus, it can be seen that a vast majority $(82.1 \%)$ of the respondents stated that they preferred the contents via video very much. Similarly, a large majority (73.2\%) indicated that they chose or liked the contents via games very much. In sharp contrast, just $10.7 \%$ of the participants said they wanted the image contents very much, while as high as $55.4 \%$ stated that they liked the image contents a little.

Following their response, the participants were asked to state and explain why their preferred multimedia was used to present the VR contents. In response, the participants frequently said and explained reasons that included Reality, interaction, interest, and ease of use when summarised. 




Figure 4.6: Participants preference for multimedia technologies used in VR

Source: Field data, 2021

It was discovered that almost all the participants very much preferred the media that made the content very realistic. For example, about the videos, one user said:

"I liked the videos most, especially the one about the movement of the leopard in the forest because it was very realistic" (User 27)

Also, the participants frequently mentioned other factors that include how interactive and engaging the content was and how easy it was to use. This means that when the participants experienced a higher feeling of Reality, ambience, interest, and ease of use of the media, they preferred the content very much. This explains why they liked the videos and game contents very much. Some of the participants expressed their reasons for liking the video, game and image contents as follows:

"I enjoyed the cell game very well. It was not only exciting; it was so alive and realistic, I felt just as if it was inside (User 13).

Playing the cell game was highly interesting. It was full of fun to me when I turned my head in different directions. Also, I was able to play the game without any difficulties (User 4).

"I liked the photography of the historical and beautiful places of Japan. It made me feel as if I was right there." (User 2).

"My favourite was the video of the submarines that I watch under the ocean. It was as if I was right inside them travelling overseas" (User 16).

On the contrary, when the users felt little or lack of Reality, interest and lack of interaction with the contents, they preferred it but a little. This is why they preferred the image or photographs but a little. Some of the participants, who didn't like the videos much due to low resolution, poor attractiveness, and low level of interaction, expressed their views as follow:

"Well, I didn't like the video I watch about the submarines because it was short, and I also didn't understand it (User 8).

"... The videos of the volcanoes and submarines would have been amazing if their image qualities were higher (User 15).

"It was okay, but then I didn't feel that the fishing game was much realistic if I'm asked." (User 22).

"... the video about the submarine, I found it difficult to understand. The image quality was also not excellent." (User 9)

As stated previously, the image (photograph) was the least preferred media. However, when the views of the participants were examined concerning their reasons for not liking it much, some of them said:

"The content I didn't like much is the photography, and I think it's because there were no such actions or movements like the game and video contents" (user 6).

"Though the pictures about the Japan trip were moving, I could not move like them. I wanted to take a walk in Japan, but there was no such option" (User 19)

\section{Participants' Views about the effectiveness of VR technologies as interactive learning tools}

The final specific objective of the study was to examine participants' views relating to the effectiveness of VR technologies as instructional tools in education. In this regard, two main questions that bothered the extent of effectiveness perceived by the participants and the subject areas they believed will be instructed more effectively through VR technologies were raised for investigation. First, based on the experienced they had from using the VR goggles to play games, watch videos, and see the photograph of past events and places, the participants were asked to indicate the extent to which they agreed or disagreed that the use of VR technologies as instructional tools will be effective in achieving the following teaching and learning goals: 
- Making learning interactive

- Encouraging active participation rather than passivity

- Visualizing abstract concepts for practical understanding

- Making learning more interesting and fun

It was realized that none of the respondents disagreed about the effectiveness of VR technologies achieving any of these stated goals; instead, they agreed. The extents to which they agreed with regard to attaining each stated benefit are summarized in Table 4.2 below.

Table 4.2: Participants' opinions of the effectiveness of VR technologies as instructional tools

\begin{tabular}{|c|c|c|c|c|c|c|}
\hline \multirow[t]{3}{*}{ Benefits } & \multicolumn{6}{|c|}{ Opinion } \\
\hline & \multicolumn{2}{|c|}{ Fairly agree } & \multicolumn{2}{|c|}{ Agree } & \multicolumn{2}{|c|}{ Completely agree } \\
\hline & $\mathrm{F}$ & $\%$ & $\mathrm{~F}$ & $\%$ & $\mathrm{~F}$ & $\%$ \\
\hline Visualizing abstract concepts & 5 & 9 & 13 & 23.4 & 37 & 66.6 \\
\hline Making learning more interactive & 7 & 12.6 & 14 & 25.2 & 35 & 63.0 \\
\hline Encouraging active participation rather than passivity & 2 & 3.6 & 21 & 37.8 & 33 & 59.4 \\
\hline Making learning more interesting and fun & 6 & 10.8 & 17 & 30.6 & 33 & 59.4 \\
\hline
\end{tabular}

As shown in Table 4.2, only a small proportion moderately agreed, while the majority as high as $66.6 \%$ of the participants ultimately agreed to all the statements about visualizing abstract concepts for practical and better understanding, which implies that VR technologies as instructional tools are essential tools as far as there's the need to help learners visualize abstract concepts to understand and apply them in practical ways. Similarly, $63.0 \%, 59.4 \%$, and $59.4 \%$ ultimately agreed that using VR technologies as instructional tools will contribute mainly to making learning interactive, encouraging active participation rather than passivity, and making learning more interesting and fun.

These discoveries made through the interview agree with advocates of using VR technologies as instructional tools in education. These advocates claim that the technology can allow students to visualize abstract concepts and take part in and interact with events that, for reasons of distance, time, scale, safety, or money, would not otherwise be possible. It is also believed that VR technologies are interactive and could make learning more exciting and fun, which could indirectly increase students' motivation and attention (Clark, 2006). As Clark, an expert educationist believed and explained, virtual reality technology can make learning more exciting and fun to improve motivation and attention, decreasing costs when using the objective and the actual environment no matter how expensive the objective simulation is. Clark further explains that VR presents an opportunity of learning with an existing situation but artificially created, facilitating the visualization and the interaction sensation with the study focus. This means that when we cannot have actual experiences, virtual Reality is irreplaceable. Furthermore, virtual reality simulation also permits us to be in challenging and dangerous situations, which are not usually accessible in the real world. It was discovered that based on their experiences, a large majority of the participants completely agreed that virtual Reality would encourage active participation rather than passivity in their classes. Popular claims were that any participant who interacts with the virtual environment is encouraged to continue interacting by seeing the results immediately. It provides an opportunity for the learner to make discoveries previously unknown. New perspectives are made possible by modelling the real world, and studying the model can provide insights never before realized (Boyle, 2016).

\section{Participants' views on subject areas that VR technologies are most required}

Secondly, the participants were asked to suggest and explain any subject areas where they thought that more effective learning could be achieved with VR technologies as instructional tools. In response, it was realized that the majority of the participants frequently mentioned Geography and environmental studies, followed by history, biology, chemistry, and physics. Finally, through the interview, some of them expressed their views and the reasons behind it as follows:

"I will appreciate it very well if our Geography teachers could let us use VR goggles to see events and be at places. This will let us enjoy the lessons most and also understand them better." (User 13)

"I have not liked the history that much, but I think that from what I have seen, I will be very interested and will be lots of fun if we are to learn history through virtual reality technologies." (User 17)

"Many times, in our science - biology, chemistry, and physics - classes, our teachers are not able to explain a lot of things to us to understand well. So, I think that it's about time they used VR technology to us." (User 2

Like the cell game I just played, our biology teachers can use games to study the human system. Like things will be evident than the books we use." (User 4).

"I am somebody I don't like social studies much, so I find social studies lessons very boring. But I believe it will be better if VR to make the lessons practical and active." (user 12).

"Yes, this technology will be very effective in our practical sessions. It could help us a lot, for example 
with VR if we are having lessons about fishes, we can go under the sea to look at fishes, how they move and do other things." (User 11).

\section{DISCUSSION OF FINDINGS, CONCLUSIONS AND RECOMMENDATIONS}

Based on empirical data, the study assessed how much VR technologies could be effective instructional tools to improve teaching and learning, especially where technology is yet to be popular.

\section{Superior aspects of VR technologies indicated by participants}

Based on the views expressed by the participants after using VR goggles and multimedia to feel and interact with various virtual reality environments, it was discovered that the degree of appreciation for different types of VR applications was significantly high. This high level of appreciation of VR applications found could be attributed to the fact that none of the participants had previously tried them for educational or entertainment purposes. However, some of them had some level of awareness about their existence. As a newly added technology in their learning environment, it could increase their curiosity as learners (Howe \& Strauss, 2000). The extant literature on VR technologies that were examined before collecting data showed that VR technologies carry the ability to stimulate the feeling of reality, ambience, pleasure or fun. They have been defined based on these and other benefits they are capable of achieving. Thus, the high rate at which the participants preferred the VR multimedia and their contents were not much of a surprise.

Notwithstanding, VR technologies have some limitations too. The participants frequently mentioned several limitations, including low resolution, eye burns, insufficient interaction, dizziness, and isolation from the real world. However, resolution and image quality were the most important issues. It is perceived that these issues inherently caused some defects to the users' feeling of Reality and ambience, which are considered as the most prominent and superior aspects of VR technologies. Examining the literature, it is pointed out that the visual quality of virtual VR technologies could be lower than the actual conditions, which would cause some problems that the users would deal with.

Furthermore, it can be said that VR technologies can cause some physical effects as well (eye burn, dizziness, etc.). This can reduce the effectiveness of VR technologies in long-term usages. Accordingly, this situation and the result that the participants recommend utilising VR technologies as support materials for instructional purposes can be more effective in learning environments that support each other.

\section{Multimedia items in VR Application Making Its Use More Interesting and Effective to Learners}

It is worth noting that the participant preferred videos and games over photographs as VR multimedia technologies. This discovery aligns with the claim of Similarly, Haluck (2000) that VR technologies are especially particularly suitable for videogames. Comparatively, users find video and game contents more realistic than photographs, and they can feel themselves in the ambience more. Furthermore, videos and games give users a higher opportunity to interact more with contents. In other words, users become more active with video and game contents, which increases their satisfaction over the images they cannot interact with very well. Interactivity was the prime feature found by researchers including Huang, Liaw, Lai (2016) \& Clark (2006) in their study. They explain that interactions in VR environments keep the learners' interests alive and make it fun to learn.

\section{Views on the effectiveness of VR technologies as instructional tools}

The most relevant objective of the study was to find out the effectiveness of VR technologies as instructional tools in education from the perspective of learners. In the context of this study, it can be said that VR technologies are significantly effective in helping to visualize abstract concepts for practical understanding, which made learning more interactive by encouraging active participation rather than passivity. These discoveries support the claims and findings of advocates and previous researchers that VR technologies can allow students to visualize abstract concepts and take part in and interact with events that, for reasons of distance, time, scale, safety, or money, would not otherwise be possible. It is also believed that VR technologies are interactive and could make learning more interesting and fun, and this could indirectly increase students' motivation and attention. Howe \& Strauss (2000) explained that VR presents an opportunity of learning with an actual situation, but artificially created, facilitating the visualization and the interaction sensation with the study focus. This means that when we cannot have real experiences, virtual Reality is irreplaceable. The virtual reality simulation also permits us to be in challenging and dangerous situations, which are not usually accessible in the real world.

Notwithstanding, several studies also indicate that those opposed to using VR technologies for instructional purposes have argued that these technologies can't be used continuously. Still, they can be used as supporting materials. However, they also have argued that VR technologies could negatively affect learners' social lives, and these practices could become tedious in time. Therefore, VR technologies in educational environments may 
not be effective because they could affect different individuals.

\section{Conclusion}

The need to employ instructional tools that facilitate teaching and learning in the classroom propelled this study. To help visualize abstract concepts and make learning interactive and interesting, VR technologies are being recommended as an instructional tool in education. A summary analysis of the empirical data revealed that the superior aspects that VR technologies provided according to the participants included a feeling of Reality, a sense of ambience, and the opportunity to tour. After playing games, watching videos and seeing pictures through virtual reality goggles, the participants frequently mentioned and talked about these superior aspects noting that they were very excited and well entertained with the experience. However, after using VR goggles to play games, watch videos and see photographs of VR environments, some of the participants frequently mentioned several limitations, including low resolution, eye burns, insufficient interaction, dizziness, and isolation from the real world as the limitations they experienced. VR uses the entire spectrum of current multimedia technologies, including image, video, sound and text, and newer and upcoming media such as e-touch, e-taste, and e-smell. The analysis of the empirical data in relation to multimedia technologies revealed that the participants' preference for VR contents presented via video and game was much higher than contents through a photograph. A vast majority of the respondents stated that they preferred the contents via video and games. In sharp contrast, just a few of the participants said they liked the contents presented through photographs.

In response to questions relating to why they preferred one multimedia over others, the participants frequently stated and explained reasons, including the feeling of Reality, interaction, excitement, and ease of use of media. It was discovered that almost all the participants very much preferred the media that made the content very realistic. On the contrary, when the users felt little or lack of Reality, interest, and lack of interaction with the contents, they preferred it but a little. This is why the participants chose not to prefer photograph contents much compared to video and game contents. Based on the experienced they had from using the VR goggles, the majority of the participants completely agreed that VR technologies as instructional tools would be effective in visualizing abstract concepts for practical understanding, making learning more interactive, encouraging active participation rather than passivity. The participants suggested and explained that more effective learning could be achieved with VR technologies as instructional tools in various subject areas. However, the majority frequently mentioned Geography and environmental studies, followed by biology, chemistry, physics and history, respectively.

In a nutshell, as discovered by this study, students at the school level appreciate the superior aspects of VR technology, including the feeling of Reality and ambience. Notwithstanding technical challenges and other limitations, in the context of this study, using VR technologies as instructional tools is generally adequate. In other words, if VR technologies are well utilized as instructional tools, a lot of positive educational goals will be achieved, including the following: visualizing abstract concepts, encouraging active participation rather than passivity, increased motivation and curiosity of learners to learn, creation of very entertaining learning environments, and learners having the opportunity to interact with objects that are difficult or impossible to be brought to class. Moreover, one cannot agree more with the observation that students of the current generation are millennials who, by nature, prefer to spend most of their time online, and some live in a virtual world (Wadhera, 2016). Since they spend most of their time online and are avid users of interconnected mobile devices, teachers need to consider having teaching materials and learning activities with similar attributes, which underscores the use of VR technologies.

\section{Recommendation}

The use of VR technologies for instructional purposes was not widespread in Abuja, where the study was conducted as discovered from this study. Thus, none of the study participants had previously used any VR technologies to explore and interact with a virtual world. Therefore, it is suggested that more forums and training workshops on the use and benefits of VR technologies as instructional tools should be embarked on in schools across the country to increase teachers and learners' interest in adopting and using these technologies in class. Furthermore, the sample participants were selected from only five schools in Abuja. Thus, the generalization of the results representing the views of junior high school students in Nigeria is not valid. Therefore, further studies should select participants from schools across the country to make generalization useful. Also, other studies could use senior high school students as participants.

\section{References}

Aarseth, E. (2001). Virtual worlds, fundamental knowledge: towards hermeneutics of virtuality, European Review, Vol. 9, No. 2, pp.227-232.

Apostolellis, P., \& Bowman, D. A. (2014). Evaluating the effects of orchestrated, game-based learning in virtual 
environments for informal education. Proceedings of the 11th Conference on Advances in Computer Entertainment Technology - ACE'14 (pp. 1-10). New York, USA: ACM Press.

Başaran, F., 2010. Teacher candidates' views on the use of virtual reality in education (Sakarya University BÖTE example). Master's Thesis, Sakarya University Institute of Social Sciences, Sakarya

Boyle, K. (2016). Citi GPS: Virtual and Augmented Reality, Citi: https.//www.privatebank.citibank.com/home/freshinsight/citi-gps-virtual-and-augmented-reality.html

Bryman, A. (2008). Social Research Methods (3rd ed.). USA: Oxford University Press Inc., New York.

Budziszewski, P. (2013). A Low Cost Virtual Reality System. Physical Therapy, 88(10), 32-39.

Check J., and Schutt R. K. (2012). Survey research. Research methods in education. Thousand Oaks, CA: Sage Publications, 159-185.

Cheung, S. K. S., Fong, J., Fong, W., Wang, F. L., \& Kwok, L. F. (Eds.) (2013). Hybrid Learning and Continuing Education (Vol. 8038). Berlin, Heidelberg: Springer.

Chung, L.-Y. (2012). Virtual Reality in college English curriculum: Case study of integrating second life in freshman English course. Proceedings of the 26th International Conference on Advanced Information Networking and Applications Workshops (pp. 250-253). Los Alamitos: IEEE Press.

Clark, D. (2006). Games and e-learning: Sunderland. Caspian Learning. http://ww.w.cedmaeurope.org/newsletter\%20articles/misc/Games\%20and\%20 Learning\%20(Nov\%2006).pdf

Critical Research Issues and Policy Implications. In Educational Technology \& Society, 17(1), 70-78.

Creswell, J.W., and Plano Clark, V.L. (2011). Designing and Conducting Mixed Method Research (2nd). CA: Sage; Thousand Oaks.

Creswell, J. W. (2009). Research design: Qualitative, quantitative, and mixed methods approaches (3rd ed.). Los Angeles: Sage.

Davis, F.D., Bagozzi, P.R., Warshaw, P. (1989). User acceptance of computer technology: a comparison of two theoretical models. In Management Science, Vol. 35, pp. 982-1003.

Fabola, A., \& Miller, A. (2016). Virtual Reality for early education: A study. In C. Allison, L. Morgado, J. Pirker, D. Beck, J. Richter \& C. Gütl (Eds.) Immersive Learning Research Network (iLRN 2016). Communications in Computer and Information Science (Vol. 621, pp. 59-72). CA: Springer.

Gomes, A., Oh, H., Chisik, Y., \& Chen, M. (2012). Ilha Musical: A CAVE for nurturing cultural appreciation. In H. Schelhowe (Ed.), Proceedings of the 11th International Conference on Interaction Design and Children (p. 232-235). Bremen, Germany: ACM Press.

Haluck, R. S. (2000). Computers and Virtual Reality for Surgical Education in the 21st Century. Archives of Surgery, 135(7), 786.

Hsiaoa, I., Lia, I., \& Lanb, Y. (2010). Development of a virtual campus on Second Life: A case study of NCU Wonderland.

Howe, N., \& Strauss, W. (2000). Millennials Rising: The Next Great Generation. Vintage Books.

Hsieh, P., Wub, Y., \& Mac, F. (2010). A study of visitor's learning needs and visit satisfaction in real and second life museums. In T. Hirashima, A. F. Mohd AYUB, 1. Kwok, S. Wong, S.C. Kong \& F. Yu (Eds.), Workshop Proceedings of the 18th International Conference on Computers in Education (pp. 248-255). Malaysia: Faculty of Educational Studies, Universiti Putra Malaysia.

Huang, H.-M., Rauch, U., \& Liaw, S.-S. (2010). Investigating learners' attitudes toward virtual reality learning environments: Based on a constructivist approach. Computers \& Education, 55(3), 1171-1182.

Huang, H.-M., Liaw, S.-S., \& Lai, C.-M. (2016). Exploring learner acceptance of the use of virtual reality in medical education: a case study of desktop and projection-based display systems. Interactive Learning Environments, 24(1), 3-19.

$\mathrm{Hu}-\mathrm{Au}, \mathrm{E}$. and Lee, J.J. (2017). Virtual Reality in education: a tool for learning in the experience age, Int. J. Innovation in Education, Vol. 4, No. 4, pp.215-226.

Kavanagh, S., Luxton-Reilly, A., Wuensche, B., \& Plimmer, B. (2017). A systematic review of Virtual Reality in education. Themes in Science and Technology Education, 10(2), 85-119.

Kaufmann, H., \& Meyer, B. (2009). Physics education in Virtual Reality: An example. Themes in Science and Technology Education, 2(1-2), 117-130.

Kiss, G. (2012). Using web conference system during the lessons in higher education. Proceedings of the 2012 International Conference on Information Technology Based Higher Education and Training (pp. 1-4). Istanbul: IEEE.

Kong, S. C., Chan, T.-W., Griffin, P., Hoppe, U., Huang, R., Kinshuk, Looi, C. K., Milrad, M., Norris, C., Nussbaum, M., Sharples, M., So, W. M. W., Soloway, E., \& Yu, S. (2014). E-learning in School Education in the Coming 10 Years for Developing 21st Century Skills:

Jacobson, J., Holden, L., Studios, F., \& Toronto, C. (2005). The Virtual Egyptian Temple. Proceedings of the 
World Conference on Educational Media, Hypermedia \& Telecommunications (ED-MEDIA).

Malhotra, N., and Birks, D. (2007). Marketing Research: An Applied Approach (3rd European Edition). Harlow, UK. Pearson Education.

Ngai, E.W.T.; Poon, J.K.L. and Chan, Y.H.C. (2005). Empirical examination of the adoption of WebCT using TAM. Computers and Education, 48. pp. 250-267

Sharma, S., Agada, R., \& Ruffin, J. (2013). Virtual reality classroom as a constructivist approach. Proceedings of the 2013 IEEE Southeastcon (pp. 1-5). IEEE. http://doi.org/10.1109/SECON.2013.6567441.

Scott, C.L. (2015). The future of learning 2: What kind of learning for the 21st century? In UNESCO Education Research and Foresight Working Papers. available online: https://unesdoc.unesco.org/ark:/48223/pf0000242996

Takala, T. (2014). RUIS: a toolkit for developing virtual reality applications with spatial interaction. In A. Wilson (Ed.), Proceedings of the 2nd ACM Symposium on Spatial Interaction (pp. 94-103). NY: ACM.

Voss, C., Tsikriktsis, N. \& Frohlich, M. (2002). Case research in operations management. International Journal of Operations \& Production Management. 22(2), 195-219.

Wadhera, M. (2016). The information age is over; welcome to the experience age', Tech Crunch, May, Vol. 9, Retrieved from https.//techcrunch.com/2016/05/09/the-information-age-is-over- welcome-tothe-experienceage

Weng, F.; Yang, R-J.; Ho, H-J. and Su, H-M. (2018). A TAM-based study of attitude towards use intention of multimedia among school teachers. Applied System Innovation, 1(36). doi: 10.3390/asi1030036

Wiecha, J., Heyden, R., Sternthal, E., \& Merialdi, M. (2010). Learning in a virtual world: Experience with using Second Life for medical education. Journal of Medical Internet Research, 12(1), e1.

Yin, R. K. (2003). Case Study Research: Design and Methods (3rd ed.). Newbury Park, CA: Sage.

Yoshida, S., Kihara, K., Takeshita, H., \& Fujii, Y. (2014). Instructive head-mounted display system: pointing device using a vision-based finger tracking technique applied to surgical education. Wideochirurgia Inne Techniki Małoinwazyjne, 9(3), 449-52.

Zhang, L., \& Liu, Q. (2012). Application of simulation and Virtual Reality to physical education and athletic training. Lecture Notes in Computer Science, 7145 LNCS, 24-33. 